\title{
NO MEIO DA TRAVESSIA
}

\section{RESUMO}

Neste artigo, são analisados comparativamente o romance de formação paradigmático Os anos de aprendizado de Wilhelm Meister, de Goethe, e Grande sertão: veredas, de João Guimarães Rosa, sob a perspectiva teórica de Mikhail Bakhtin.

\section{ABSTRACT}

In this article, the paradigmatic Bildungsroman Wilhelm Meister's Apprenticeship, by Goethe, and Grande sertão: veredas, by João Guimarães Rosa, are analyzed comparatively under the theoretical perspective of Mikhail Bakhtin.

\section{PALAVRAS-CHAVE:}

Romance de formação; Goethe;

Guimarães Rosa;

Bakhtin;

Cronótopo;

Dialogismo.

\section{KEYWORDS:}

Bildungsroman;

Goethe;

Guimarães Rosa;

Bakhtin;

Chronotope;

Dialogism. 
"O real não está na saída nem na chegada: ele se dispõe para a gente é no meio da travessia."

João Guimarães Rosa

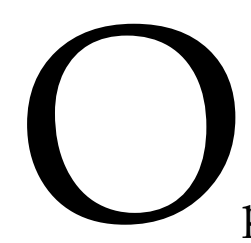

pensador russo Mikhail Bakhtin construiu um referencial teórico relevante acerca das obras de Dostoiévski e de Rabelais. Problemas da Poética de Dostoiévski e A Cultura Popular na Idade Média e no Renascimento - O contexto de François Rabelais são títulos fundamentais para a pesquisa não só desses romancistas como também para a compreensão da história da arte literária no Ocidente. $\mathrm{O}$ terceiro grande escritor ao qual se dedicou o ensaísta foi Goethe, que, conforme biógrafos de Bakhtin, "desempenhou papel imenso no pensamento do crítico russo durante toda a sua vida" 1 . Contudo, enquanto as obras sobre Dostoiévski e Rabelais foram publicadas na íntegra - a primeira em 1929 e, revisada pelo autor, em 1963; a segunda em 1965 -, do livro sobre Goethe, escrito entre 1936 e 1938, restaram apenas fragmentos. Os originais chegaram a ser entregues para a editora, mas a deflagração da II Guerra Mundial interrompeu o processo e o texto integral desapareceu ${ }^{2}$. Com o título "O romance de educação e sua importância na história do realismo" foram publicados postumamente, na coletânea Estética da Criação Verbal ${ }^{3}$, três fragmentos arrolados entre os materiais preparatórios do livro, os quais indicam ser "Goethe e o romance de educação" o tema central da obra ${ }^{4}$.

Como é frequente em Bakhtin, no plano desse trabalho ele privilegia a contextualização histórica, iniciando por uma visão abrangente, que compreende amplos períodos e abarca as raízes da constituição e evolução da forma romanesca, para depois restringir a análise, desenhando uma tipologia de romances de formação, cujas variações podem se mesclar, assim como se altera o "grau de assimilação do tempo histórico real" 5 . São estes os tipos de romance de formação mencionados por Bakhtin: o de natureza cíclico-idílica, em que se apresenta a sucessão das fases da vida e as transformações decorrentes da idade; o que supera a simples divisão etária e descreve a trajetória do herói do idealismo juvenil ao pragmatismo

\footnotetext{
${ }^{1}$ Katerina Clark, Michael Holquist, Mikhail Bakhtin. São Paulo: Perspectiva, 1998, p. 290.

2 Idem, ibidem, p. 335.

3 Mikhail Bakhtin. Estética da Criação Verbal. São Paulo: Martins Fontes, 2011. Publicado originalmente na União Soviética em 1979.

4 Idem, ibidem. Conforme Nota do tradutor Paulo Bezerra, p. 441.

${ }^{5}$ Idem, ibidem, p. 220.
}

132 | D O S S I Ê : ROMANCE DE FORMAÇ̃̃O - CAMINHOS E DESCAMINHOS DO HERÓI 
da maturidade, tido pelo ensaísta como o tipo clássico de romance de formação; o biográfico ou autobiográfico, que leva em conta as condições de vida e os acontecimentos para a formação do indivíduo; o didáticopedagógico, em cujo cerne se encerra claramente uma proposição dessa espécie. Por fim, cita aquele que considera ser o mais importante tipo de romance de formação: "Nele, a formação do homem se apresenta em indissolúvel relação com a formação histórica. A formação do homem efetua-se no tempo histórico real com sua necessidade, com sua plenitude, com seu futuro, com seu caráter profundamente cronotópico" 6 .

Nesse sentido, a formação se dá em perspectiva histórica, com a dinâmica da formação individual ocorrendo em interação com um mundo também em transformação, o que leva a um desenvolvimento cujos resultados não são particulares, pois acontece concomitante e reflexivamente a um movimento coletivo. Para Bakhtin, esse é o tipo de romance de formação realista, em que o herói que se forma reflete a imagem do homem numa época de transição histórica em um lugar determinado, aspecto relevante em Os anos de aprendizado de Wilhelm Meister ${ }^{7}$ e em importantes romances de formação, entre os quais incluímos Grande sertão: veredas, abordado em chave comparativa nesta análise.

Conforme aponta Marcus Mazzari ${ }^{8}$, a narrativa de Guimarães Rosa, apesar de oscilar entre o fáustico e a formação, pode ser considerada um legítimo exemplar de romance de formação e desenvolvimento, uma vez que coloca "em primeiro plano a trajetória de um homem pelas vicissitudes e contradições da realidade, (...) sofrendo revezes e amadurecendo paulatinamente no sentido de uma conscientização de seu papel no mundo"9.

\section{Origens e História}

Embora o caminho traçado por Riobaldo siga, em linhas gerais, o roteiro de formação prototípico - a saída da casa do pai, as aventuras e experiências adquiridas na estrada, as quais configuram o período de aprendizado, e, por fim, a reconciliação com a realidade assumindo a condição paterna herdada -, destacamos dois pontos em que esse percurso

\footnotetext{
${ }^{6}$ Idem, ibidem, p. 221

7 Johann Wolfgang von Goethe, Os anos de aprendizado de Wilhelm Meister. São Paulo: Editora 34, 2006. No posfácio dessa edição consta o ensaio em que Georg Lukács também ressalta a perspectiva histórica desse romance, porém de um prisma diferente da visão de Bakhtin, relacionando-o diretamente com transformações decorrentes da Revolução Francesa. Já Erich Auerbach, em Mimesis (São Paulo: Perspectiva, 2002, p .400), posiciona-se contrariamente, considerando que em Os anos de aprendizado de Wilhelm Meister "o mundo da classe média repousa diante dos olhos do leitor numa calma quase atemporal".

${ }^{8}$ Marcus Vinicius Mazzari, Labirintos da aprendizagem - Pacto fáustico, romance de formação e outros temas de literatura comparada. São Paulo: Editora 34, 2010.

${ }^{9}$ Idem, ibidem, p. 90.
}

133 | D O S S I Ê : ROMANCE DE FORMAÇ̃̃O-CAMINHOS E DESCAMINHOS DO HERÓI 
se distancia daquele descrito pelo herói paradigmático do romance de formação, com implicações no próprio processo de desenvolvimento do protagonista. O primeiro deles é a origem de Riobaldo, bem diferente da de Wilhelm Meister, o que assinala distinções de ordem histórica entre as épocas e os lugares onde se passam os respectivos enredos. Assim, mesmo sendo ambas as narrativas deliberadamente marcadas por um esfumaçamento de datas, fatos e referências históricas precisas, tais dados da biografia de cada um dos heróis, assim como muitos outros detalhes e caracterizações distribuídos ao longo dos romances, contribuem para contextualizar as obras no tempo e no espaço de uma realidade identificável pelo leitor. Isso significa que os autores não se furtaram a integrar ao cenário e à trama conflitos e contradições peculiares ao local e ao momento histórico, embora o processo interior dos protagonistas seja preponderante, privilegiando a percepção temporal e espacial vivenciada pelos heróis. De qualquer forma, "por trás da totalidade do romance está essa grande totalidade real do mundo e da história"10.

A despeito da consciência que Wilhelm tem das limitações socialmente impostas à sua condição burguesa, ele não é de "escuro nascimento" 11 como Riobaldo, que passou a infância como agregado da família Guedes e, depois de perder a mãe, é recebido na fazenda São Gregório, onde vive "na lordeza"12, mas ainda em situação de amparo, agora por parte do padrinho Selorico Mendes, que, todavia, proporciona ao protagonista acesso à formação escolar básica. Quando Riobaldo descobre que o protetor é, na verdade, seu pai biológico, foge da casa paterna, motivo bem diverso do sentimento de busca por formação, conforme explicita Wilhelm na carta em que declara a sua escolha pelo teatro: "Para dizer-te em uma palavra: instruir-me a mim mesmo, tal como sou, tem sido obscuramente meu desejo e minha intenção, desde a infância." 13 Dessa forma, enquanto Wilhelm abandona uma vida estável e previsível à procura de uma alternativa ao seu destino burguês, firmemente delineado pela condição familiar, de acordo com a estrutura social, Riobaldo, cuja origem está na classe mais humilde, deixa a casa paterna levando consigo a dolorida revelação da ascendência até então obscura, acompanhada de uma sensação de não pertencimento: "Aquela hora eu queria só gente estranha, muito estrangeira, estrangeira inteira!"14, diz o protagonista, expressando não só a vergonha e necessidade de se

\footnotetext{
${ }^{10}$ M. Bakhtin. Estética da Criação Verbal, op. cit, p. 249.

${ }^{11}$ João Guimarães Rosa. Grande sertão: veredas. Rio de Janeiro: José Olympio, 1976, p. 35

12 Idem, ibidem, p. 95.

${ }^{13} \mathrm{~J}$. W. Goethe, Os anos de aprendizado de Wilhelm Meister, op. cit., p. 284. Em Labirintos da aprendizagem, op. cit., p. 109, Marcus Mazzari utiliza a seguinte tradução desse trecho: "Para dizerte em uma palavra: formar-me plenamente, tomando-me tal como existo, isto sempre foi, desde a primeira juventude e de maneira pouco clara, o meu desejo e a minha intenção".

14 J. G. Rosa, Grande sertão: veredas, op. cit., p. 96.
}

134 | D O S S I Ê : ROMANCE DE FORMAÇ̃̃O-CAMINHOS E DESCAMINHOS DO HERÓI 
libertar do fato recém-revelado, mas também uma identificação com aqueles de origem e destino desconhecidos, de frágeis raízes, à deriva, como ocorre consigo. Esse sentimento de perceber-se estranho em um grupo e estrangeiro em um lugar, de se sentir diferente dos demais jagunços, persiste, evidenciando-se em seu discurso e em vários episódios da trama, inclusive atuando como força propulsora para o seu desenvolvimento e influenciando suas escolhas.

Mesmo se tratando de classes sociais distintas, podemos considerar esses dados biográficos dos protagonistas reveladores do aguçado sentido de tempo histórico dos autores, pois configuram a condição particular de origem dos heróis em conexão com a realidade, com os valores e circunstâncias correntes nos respectivos locais e épocas, condição essa plena de significados e reverberações da situação social e política em que se dá a formação. Especialmente em Os anos de aprendizado de Wilhelm Meister, essa caracterização é determinante para o desenrolar da história, mas também em Grande sertão: veredas a menção à filiação do protagonista é oportunidade para o autor pontuar, ainda que de forma sutil, o fenômeno da migração da população pobre no Brasil e o consequente desenraizamento e abandono da família.

Órfão de conhecença e de papéis legais, é o que a gente vê mais, nestes sertões. Homem viaja, arrancha, passa: muda de lugar e de mulher, algum filho é o perdurado. Quem é pobre, pouco se apega, é um giro-o-giro no vago dos gerais, que nem os pássaros de rios e lagoas. O senhor vê: o Zé-Zim, o melhor meeiro meu aqui, risonho e habilidoso. Pergunto: - "Zé-Zim, por que é que você não cria galinhas-d'angola, como todo o mundo faz?" "- Quero criar nada não..." - me deu resposta: - "Eu gosto muito de mudar..." Está aí, está com uma mocinha cabocla em casa, dois filhos dela já tem. Belo um dia, ele tora. É assim. Ninguém discrepa. ${ }^{15}$

A elucidação da conjuntura de infância, ou seja, do contexto embrionário da formação dos heróis, é exposta na parte inicial das obras. Wilhelm relata para sua amada Mariane, com enlevo e riqueza de detalhes acerca do ambiente doméstico burguês em que vivia, episódios que enfatizam o seu gosto pelo teatro desde tenra idade. Já Riobaldo, dono de uma memória prodigiosa, afirma recordar tudo da fase de meninice. "Me lembro dela com agrado; mas sem saudade. Porque logo sufusa uma aragem dos acasos."16. A despeito da disparidade das condições, o exemplo demonstra o caráter cronotópico das obras, que contam com muitas outras passagens capazes de contextualizar historicamente $\mathrm{o}$ enredo sem se valer de menções históricas diretas. No caso de Os anos de aprendizado de Wilhelm Meister, Bakhtin faz uma analogia da representação

${ }^{15}$ Idem, ibidem, p. 35.

16 J. G. Rosa, Grande sertão: veredas, op. cit., p. 35.

135 | D O S S I Ê : ROMANCE DE FORMAÇ̃̃O - CAMINHOS E DESCAMINHOS DO HERÓI 
profunda, mas não óbvia, dos fundamentos socioeconômicos, políticos e morais no romance com a pulsação das montanhas, conforme uma ideia do próprio Goethe de que a atividade imperceptível das montanhas interferiria no clima. "Em Wilhelm Meister, esse fundo dos alicerces do mundo começa a pulsar como os maciços no exemplo citado, e essa pulsação determina o movimento mais superficial e a mudança dos destinos humanos e das concepções humanas"17.

Tomado das ciências exatas, o termo cronótopo significa, literalmente, tempo-espaço. O conceito aparece no trabalho sobre Goethe e posteriormente foi desenvolvido por Bakhtin na sua teoria do romance ${ }^{18}$. No "esboço relativamente concluído sobre o tempo e o espaço nas obras de Goethe" 19, publicado em Estética da criação verbal, o teórico russo frisa a capacidade visual, a acuidade ao contemplar o espaço e o senso de concretude do escritor, que conseguia "ler os indícios do curso do tempo em tudo" 20 , ilustrando com relatos do poeta sobre sua viagem à Itália e outros textos autobiográficos. Bakhtin afirma que essa é a ideia de formação para Goethe, processo que não se limita ao homem, pois o observa na natureza e em tudo o que é transformado por mãos humanas, em uma continuidade ininterrupta, de maneira a ver o passado no presente e este no futuro ${ }^{21}$.

Um artista como Goethe, por exemplo, tende para a série em formação. Procura perceber todas as contradições existentes como diferentes etapas de um desenvolvimento uno, tende a ver em cada fenômeno do presente um vestígio do passado, o ápice da atualidade ou uma tendência do futuro. 22

Em Questões de literatura e de estética - A teoria do romance ${ }^{23}$, Bakhtin retoma e desenvolve o conceito de cronótopo. Sem perder a abrangência da ideia tal como se apresenta no texto acerca da obra de Goethe, delimita a representação da relação entre tempo e espaço à artisticamente assimilada na literatura. Assim, cronótopos são unidades de conteúdo que aliam, de forma indissolúvel, aspectos de tempo e espaço e possibilitam o

\footnotetext{
${ }^{17}$ M. Bakhtin, Estética da Criação Verbal, op. cit., p. 231

${ }^{18}$ Idem, ibidem, p. 440. Nota do tradutor Paulo Bezerra.

${ }^{19}$ Idem, ibidem, p. 441. Nota do tradutor Paulo Bezerra.

${ }^{20}$ Idem, ibidem, p. 229, grifo do autor.

${ }^{21}$ Tal pensamento coaduna-se com um aspecto do conceito de carnavalização, elaborado por Bakhtin a partir do estudo da obra de Rabelais. O teórico enfatiza a ambivalência das imagens da morte e do nascimento, pois o velho traz em si o novo e o novo ainda faz parte do velho. Nesse sentido, a permanência se dá pela impermanência, pela morte do ser que sobrevive no novo ser. "Onde há morte, há também nascimento, alternância, renovação" (Mikhail Bakhtin, A cultura popular na Idade Média e no Renascimento - O contexto de François Rabelais. São Paulo: Hucitec, 2008, p. 359). Assim, o conceito de carnavalização reforça a dinâmica em que se aliam os polos negativo e positivo, morte e vida, não havendo, portanto, polaridade estática, mas movimento e transformação constantes.

${ }^{22}$ Mikahil Bakhtin, Problemas da poética de Dostoiévski. Rio de Janeiro: Forense, 2010, p. 31.

${ }^{23}$ Mikahil Bakhtin, Questões de literatura e de estética - A teoria do romance. São Paulo: Hucitec, 2010.
}

136 | D O S S I Ê : ROMANCE DE FORMAÇ̃̃O-CAMINHOS E DESCAMINHOS DO HERÓI 
andamento do enredo. "Eles são os centros organizadores dos principais acontecimentos temáticos do romance. É no cronotopo que os nós do enredo são feitos e desfeitos." 24

Dois tipos de cronótopo basilares e interligados, frequentes na representação literária desde a Antiguidade, são constitutivos dos romances em análise: o cronótopo do encontro e o cronótopo da estrada ${ }^{25}$. Tanto Wilhelm quanto Riobaldo passam seus anos de aprendizado na estrada, transitando pelo país natal, pois não se trata aqui de aventuras em paisagens exóticas, e ambos são marcados por encontros decisivos para o desenrolar do enredo. Bakhtin destaca a enorme importância do motivo do encontro, em que são indissociáveis as noções de tempo e de espaço - para que o encontro ocorra é preciso que os elementos estejam no mesmo momento em um único lugar - e pode se caracterizar por forte intensidade emocional. $\mathrm{O}$ cronótopo da estrada também reflete com muita clareza a unidade indissolúvel tempo-espaço, podendo trazer as marcas do transcurso do tempo histórico e sinais da época ${ }^{26}$.

No romance, os encontros ocorrem frequentemente na "estrada". Ela é o lugar preferido dos encontros casuais. Na estrada ("a grande estrada") cruzam-se num único ponto espacial e temporal os caminhos espaçotemporais das mais diferentes pessoas, representantes de todas as classes, situações, religiões, nacionalidade, idade. Aqui podem se encontrar por acaso, as pessoas normalmente separadas pela hierarquia social e pelo espaço, podem surgir contrastes de toda espécie, chocarem-se e entrelaçarem-se diversos destinos. ${ }^{27}$

\section{Acaso e destino}

Neste ponto, tangenciamos outro aspecto em que as trajetórias formativas dos heróis se distanciam. O caminho de Riobaldo, do nascimento ao período de andanças, ocorre de maneira aleatória, ao sabor do acaso e do destino. Já Wilhelm, mesmo argumentando em favor desses dois fatores, tem encontros que não são casuais, embora ele desconheça que sua formação está sendo guiada. Nesses contatos aparentemente fortuitos com pessoas que depois se revelarão responsáveis por seu desenvolvimento, Wilhelm é contestado a respeito do valor que dá ao destino.

A trama deste mundo é tecida pela necessidade e pelo acaso; a razão do homem se situa entre os dois e sabe dominá-los; ela trata o necessário como a base de sua existência; sabe desviar, conduzir e aproveitar o acaso, e só

\footnotetext{
${ }^{24}$ Idem, ibidem, p. 355.

${ }^{25}$ Idem, ibidem, p. 222-223.

${ }^{26} \mathrm{Idem}$, ibidem, p. 350.

${ }^{27}$ Idem, ibidem, p. 349.
}

137 | D O S S I Ê : ROMANCE DE FORMAÇ̃̃O - CAMINHOS E DESCAMINHOS DO HERÓI 
enquanto se mantém firme e inquebrantável é que o homem merece ser chamado um deus na Terra. ${ }^{28}$

Firme e inquebrantável não se mostra o herói goetheano e tampouco chegará a ser o hesitante Riobaldo, ambos marcados por dúvidas, questionamentos e conflitos interiores. Contudo, enquanto este se autodefine "um pobre menino do destino" 29 - sintagma em que os termos se reforçam mutuamente para dar corpo à ideia de que o personagem foi sempre levado pelas circunstâncias, o que também justificaria seus atos -, Wilhelm demonstra, desde cedo, um interesse, um propósito, uma aptidão. "Acreditava entender o claro sinal do destino que, através de Mariane, lhe estendia a mão para arrancá-lo àquela arrastada e inerte vida burguesa, da qual há muito desejara se libertar. (...) Não tinha mais dúvida alguma de que fora destinado para o teatro" 30 . Questão perene na literatura, o destino da vida humana está no centro dos romances de Goethe e de Guimarães Rosa. O primeiro, que escreveu Os anos de aprendizado de Wilhelm Meister sob os influxos revolucionários de uma época de intensa transição para a sociedade europeia, busca mostrar a possibilidade de limitar o arbítrio do destino por meio da razão e do desenvolvimento das potencialidades humanas, visando à evolução individual em prol também da coletividade, de acordo com pressupostos humanistas. Eis outra manifestação do educador de Wilhelm:

- O destino - replicou o outro, sorrindo - é um preceptor excelente, mas oneroso. Eu preferiria ater-me ao julgamento de um mestre humano. $\mathrm{O}$ destino, a cuja sabedoria rendo total respeito, tem no acaso, por meio do qual age, um órgão muito canhestro. Pois raras são as vezes em que este parece realizar com acerto e precisão o que aquele havia determinado. ${ }^{31}$

Já Guimarães Rosa salienta a ambiguidade, a inconstância da vida e as forças imponderáveis, externas e internas, diante das quais o ser humano defronta-se permanentemente. Ele expõe teses como as "pessoas ainda não foram terminadas" 32 e "tudo é e não é"33, ressaltando a impossibilidade de completude e a precariedade da condição humana instável, inacabada e inapreensível -, tão bem metaforizada na imagem do rio, em seu movimento perpétuo, sempre novo e nunca repetido. Tantos anos depois dos acontecimentos, Riobaldo ainda pergunta a si mesmo e ao seu interlocutor:

\footnotetext{
${ }^{28} \mathrm{~J}$. W. Goethe, Os anos de aprendizado de Wilhelm Meister, op. cit., p. 83.

29 J. G. Rosa, Grande sertão: veredas, op. cit., p. 16.

${ }^{30}$ Idem, ibidem, p. 50.

${ }^{31} \mathrm{~J}$. W. Goethe, Os anos de aprendizado de Wilhelm Meister, op. cit., p. 127.

32 J. G. Rosa, Grande sertão: veredas, op. cit., p. 20.

33 Idem, ibidem, op. cit., p. 12.
}

138 | D O S S I Ê : ROMANCE DE FORMAÇ̃̃O - CAMINHOS E DESCAMINHOS DO HERÓI 
Por que foi que eu conheci aquele Menino? O senhor não conheceu, compadre meu Quelemém não conheceu, milhões de milhares de pessoas não conheceram. O senhor pense outra vez, repense o bem pensado: para que foi que eu tive de atravessar o rio, defronte com o Menino? (...) Deveras se vê que o viver da gente não é tão cerzidinho assim?34

Aqui não há espaço para o utópico projeto educativo da Sociedade da Torre - que acompanhou Wilhelm durante seu aprendizado -, mas a chamada para uma reflexão sobre quanto o destino pode ter de aleatório e de volitivo em cada circunstância que se nos apresenta; como somos levados por paixões e pulsões e, animais racionais, agimos emocionalmente, sendo conduzidos pelo afeto às nossas escolhas; quanto a realidade é cambiante e fugidia. "De noite o destino da gente às vezes conversa, sussurra, explica, até pede para não se atrapalhar o devido, mas ajudar. Crendice? Mas coração não é meio destino?"35 Uma síntese que aproxima as posições dos dois autores - Goethe direcionado para a razão, a despeito da sensibilidade de seu personagem; Guimarães Rosa ressaltando a vulnerabilidade emocional a que o ser humano está sujeito, e ambos traçando o longo arco de desenvolvimento dos respectivos protagonistas -, é proposta por Marcus Mazzari como "um 'estar a caminho' rumo a uma maestria ou sabedoria de vida, que Goethe representa todavia menos como meta a ser efetivamente alcançada do que como direção ou referência a ser seguida" 36 . Nesse sentido, a formação não se completa, prossegue ao longo da vida, como se pode constatar no reflexivo Riobaldo, que, ao baldear de uma margem à outra a sua história, aprimora a compreensão da existência humana, mesmo diante da impossibilidade de abarcar todos os seus mistérios.

\section{Aprendizado pelo amor}

O sofrimento provocado pelo amor - "uma dura escola" 37 , conforme qualifica o narrador goethiano - e pela morte do ser amado é relevante no percurso de aprendizado de ambos os heróis. A paixão e a dor por ela causada promovem transformações que podem redundar em uma jornada de amadurecimento e autoconhecimento. Após o violento golpe ocasionado pela morte e revelação da verdadeira identidade de Diadorim, o herói de Grande sertão: veredas ultima o jagunço Riobaldo e se "desapodera" 38 , sai errante pelos caminhos, adoece, perde os sentidos e a

\footnotetext{
${ }^{34}$ Idem, ibidem, p. 86.

${ }^{35}$ Idem, ibidem, p. 302.

${ }^{36}$ M. Mazzari, in J. W. Goethe, Os anos de aprendizado de Wilhelm Meister, op. cit., p. 14.

$37 \mathrm{~J}$. W. Goethe, Os anos de aprendizado de Wilhelm Meister, op. cit., p. 32.

38 J. G. Rosa, Grande sertão: veredas, op. cit., p. 455.
}

139 | D O S S I Ê : ROMANCE DE FORMAÇ̃̃O - CAMINHOS E DESCAMINHOS DO HERÓI 
memória - "Eu estava um saco cheio de pedras" 39 . No entanto, é essa experiência solitária, de consternação e tristeza profunda, com seu potencial transformador, que proporciona a ruptura capaz de levar o protagonista a avaliar sua trajetória e galgar um novo patamar de consciência. Todavia, o processo de formação ocorre ininterrupta e gradualmente, por meio de tais vivências complexas e excepcionais, mas também pelas cotidianas e intuitivas, que se acumulam e se conectam, dando sentido à vida. Tal processo, portanto, não acontece de forma "cerzidinha", pois quase sempre percorre rotas inesperadas para levar a objetivos que, no final, podem se revelar distantes daqueles inicialmente imaginados.

Eu atravesso as coisas - e no meio da travessia não vejo! - só estava era entretido na idéia dos lugares de saída e de chegada. Assaz o senhor sabe: a gente quer passar um rio a nado, e passa; mas vai dar na outra banda é num ponto muito mais embaixo, bem diverso do em que primeiro se pensou. ${ }^{40}$

Conjunto imagético semelhante é usado por Goethe para ilustrar o momento em que Wilhelm é orientado a ler Shakespeare, o que influenciará no seu desenvolvimento e elevará o seu conhecimento da arte dramática.

Por vezes, estando próximo de uma evolução de suas forças, de suas capacidades e de seus conceitos, o homem cai numa perplexidade da qual pode facilmente livrá-lo um bom amigo. Assemelha-se então a um andarilho que, não longe de seu albergue, cai na água; se alguém lhe esticasse de pronto a mão e o puxasse para a terra, tudo não teria passado de um banho, ao passo que, se ele próprio tivesse se livrado por si só e saído na outra margem, teria feito um longo e penoso desvio rumo a seu objetivo determinado. ${ }^{41}$

Para Wilhelm, o sofrimento decorrente da morte da amada também é significativo, mas essa fatalidade é amenizada pela revelação de ela ter lhe deixado um filho, do qual não tinha conhecimento até então. Feliz com o horizonte que se abre diante de si por essa nova vida, com "o sentimento de pai" 42 , chega ao fim de seus anos de aprendizado e então expressa o verdadeiro sentido da formação, conforme Bakhtin atribui a Goethe e semelhante ao conteúdo das citações acima:

Tudo que pensava plantar devia crescer ao encontro do menino, e tudo que estabelecesse devia durar por várias gerações. (...)

\footnotetext{
${ }^{39}$ Idem, ibidem, p. 457.

${ }^{40}$ Idem, ibidem, p. 30.

${ }^{41} \mathrm{~J}$. W. Goethe, Os anos de aprendizado de Wilhelm Meister, op. cit., p. 184.

42 Idem, ibidem, p. 479.
} 
- Oh, que inútil severidade da moral, quando a natureza, a seu modo amoroso, nos forma para tudo aquilo que devemos ser! (...) Pobre de toda forma de cultura que destrói os meios mais eficazes da verdadeira formação e nos indica o fim, ao invés de nos tornar felizes no caminho, propriamente! ${ }^{43}$

Nesse momento de mudança de condição, em que, como pai, deve estar apto a dar respostas ao filho que está descobrindo o mundo, Wilhelm sente "a necessidade de se instruir sendo convocado para ensinar" 44 , para em seguida perceber que "na verdade era mais o menino que o educava do que ele ao menino" 45. Também Riobaldo declara: "Mestre não é quem sempre ensina, mas quem de repente aprende" 46 e no final da narrativa, quando reencontra Zé Bebelo, ouve deste: “'- A bom, eu não te ensinei; mas bem te aprendi a saber certa a vida..."' 47 Assim colocadas, ensinar e aprender são ações que "são as quase iguais" 48 , parodiando a resposta do Compadre meu Quelemém à questão crucial de Riobaldo, se vendou ou não a alma ao diabo.

Tal dialética remete a outro conceito bakhtiniano, uma vez que demonstra quão dialógico é o aprendizado. Considerada por Paulo Bezerra a "quintessência da teoria bakhtiniana do discurso" 49, a concepção de dialogismo é fulcral no pensamento do ensaísta russo e ultrapassa os limites do romance, abarcando a sua feitura, na relação autor-personagem; a sua recepção, na relação obra-leitor, podendo-se incluir aqui o diálogo entre autores por meio de suas obras; e se constituindo também na vida da palavra no dia a dia de indivíduos reais.

As relações dialógicas - fenômeno bem mais amplo do que as relações entre as réplicas do diálogo expresso composicionalmente - são um fenômeno quase universal, que penetra toda a linguagem humana e todas as relações e manifestações da vida humana, em suma, tudo o que tem sentido e importância. ${ }^{50}$

Riobaldo, cujo talento pedagógico logo fora identificado pelo professor das primeiras letras ${ }^{51}$, iniciou a vida autônoma dando aulas a Zé Bebelo ${ }^{52}$, com o qual estabeleceu um convívio que transcendeu a tarefa didática, pois se configurou de forma dialógica no sentido da aprendizagem mútua. Riobaldo admira a inteligência, o tirocínio e a

${ }^{43}$ Idem, ibidem, p. 479.

${ }^{44}$ Idem, ibidem, p. 475.

${ }^{45}$ Idem, ibidem, p. 480.

46 J. G. Rosa, Grande sertão: veredas, op. cit., p. 235.

${ }^{47}$ Idem, ibidem, p. 459.

${ }^{48} \mathrm{Idem}$, ibidem, p. 460.

${ }^{49}$ Paulo Bezerra, Prefácio, In: Mikhail Bakhtin, Problemas da poética de Dostoiévski, op. cit., p. V.

${ }^{50}$ Idem, ibidem, p. 47.

${ }^{51}$ J. G. Rosa, Grande sertão: veredas, op. cit., p. 89.

52 Idem, ibidem, p. 99.

141 | D O S S I Ê : ROMANCE DE FORMAČ̃̃ - CAMINHOS E DESCAMINHOS DO HERÓI 
capacidade expressiva desse chefe, que se torna um modelo para ele e de quem absorve importantes lições de vida ${ }^{53}$. Em diversas circunstâncias, pautava suas ações questionando-se qual seria a atitude de Zé Bebelo diante da situação, e teve oportunidade de demonstrar a sagacidade e habilidade retórica aprendidas com o líder em episódios como o julgamento do próprio Zé Bebelo e, em uma reviravolta do enredo, ao confrontar com este e lhe tomar o poder. Mas, por fim, foi no reencontro dos dois, após transcorrida a história, que Zé Bebelo conduziu Riobaldo àquele que se tornou seu mentor espiritual, o kardecista Compadre meu Quelemém, citado ao longo da narrativa. Além desses dois preceptores, há ainda Diadorim, que dialógica e amorosamente ensina Riobaldo não só o valor da coragem, mas também a se lembrar da bondade da mãe ${ }^{54}$; a adotar hábitos de higiene e cuidados pessoais ${ }^{55}$; até a amar Otacília, quando se põe a descrever o imaginado futuro casamento em que não há espaço para ele, Diadorim ${ }^{56}$; e, recorrentemente, a apreciar as belezas da natureza.

O Reinaldo mesmo chamou minha atenção. O comum: essas garças, enfileirantes, de toda brancura; o jaburu; o pato-verde, o pato-preto, topetudo; marrequinhos dançantes; martim-pescador; mergulhão; e até uns urubús, com aquele triste preto que mancha. (...)

Até aquela ocasião, eu nunca tinha ouvido dizer de se parar apreciando, por prazer de enfeite, a vida mera deles pássaros, em seu começar e descomeçar dos vôos e pousação. Aquilo era para se pegar a espingarda e caçar. ${ }^{57}$

Esse tipo de aprendizado informal e constante decorre da "natureza dialógica do pensamento humano" 58 , resultando da interação de consciências em diálogo, de maneira que o discurso reverbera a palavra do outro e provoca uma réplica, que por sua vez ecoa na outra consciência, a qual reage em consonância ou dissonância, provocando um entrelaçamento das próprias palavras com as alheias e repercutindo na consciência com desdobramentos nos discursos. Fenômeno afim é descrito por Riobaldo: "a opinião das outras pessoas vai se escorrendo delas, sorrateira, e se mescla aos tantos, mesmo sem a gente saber, com a maneira da idéia da gente!"59. É dessa forma dialógica que ele aprende o passo a passo para fazer o pacto, ouvindo conversas, perguntando a companheiros, inteirando-se de detalhes e observando o pactário Hermógenes.

\footnotetext{
53 Ver M. V. Mazzari, op. cit., p. 82-83.

${ }^{54}$ J. G. Rosa, Grande sertão: veredas, op. cit., p. 34.

${ }^{55}$ Idem, ibidem, p. 113.

${ }^{56}$ Idem, ibidem, p. 285-286.

${ }^{57}$ Idem, ibidem, op. cit., p. 111.

${ }^{58}$ Mikhail Bakhtin. Problemas da poética de Dostoiévski, op. cit., p. 98.

${ }^{59}$ J. G. Rosa, Grande sertão: veredas, op. cit., p. 349.
}

142 | D O S S I Ê : ROMANCE DE FORMAÇ̃̃O - CAMINHOS E DESCAMINHOS DO HERÓI 
Em Os anos de aprendizado de Wilhelm Meister, essa formação aleatória e inevitável, efeito da interação dialógica de consciências, soa um tanto negativa na voz do narrador, que condena o comportamento de Wilhelm de procurar conhecer opiniões e experiências de terceiros, por meio de conversações ou livros, e as valorizar excessivamente, "o que vinha sempre dar em erro. (...) retendo infelizmente dessa maneira tanto o falso quanto o verdadeiro, (...) perdendo assim sua natural maneira de pensar e de agir ao seguir no mais das vezes luzes estranhas como se fossem estrelas-guias" 60 . Por outro lado, é justamente o fato de não assimilar um ensinamento, de se fechar a uma palavra alheia, que salva da morte o pequeno Felix, filho de Wilhelm. Órfão de mãe desde o nascimento e ainda sem saber quem era o pai, o menino vivia sob os cuidados da atriz Aurelie, que, atormentada por uma frustração amorosa, era impaciente e intolerante com a criança. Esta retribuía com um comportamento agitado e desobediente, como o hábito de beber água diretamente da garrafa, o que irritava sobremaneira Aurelie. Em uma circunstância trágica, supõe-se que o menino tenha bebido o líquido envenenado que estava em um copo, o que ele mesmo confirma, pois conhece a regra de boas maneiras, mas mentia por temer censura e punição. Na realidade, ele havia ingerido o conteúdo da garrafa que estava junto ao copo e não continha veneno. Assim, a atitude de não aderir a uma norma de educação, de não ser "educado", evita a fatalidade e preserva a vida do garoto.

Nesse sentido, a formação pode se dar quase "às avessas", como também fica patente na trajetória de Serlo. O desenvolvimento desse ator, talentoso por natureza, começa com maus-tratos na infância, pois o pai acreditava nos efeitos pedagógicos das surras. Jovem e tecnicamente evoluído na arte da imitação, foge da casa paterna e, durante suas peripécias, vivencia outras experiências de natureza violenta, porém apresentadas de forma paródica, em imagens que dialogam com a obra de François Rabelais ${ }^{61}$. Serlo iniciou representando farsas picarescas, depois assumiu a organização de mascaradas clericais em um convento, saindose muito bem ao interpretar papeis cada vez mais importantes em peças religiosas e "finalmente, como Salvador do mundo, mereceu ser escarnecido, flagelado e pregado na cruz" 62, o que foi feito com "excessiva naturalidade" 63 por alguns dos figurantes. Para vingar-se destes, planeja um estratagema e os espanca na cena do Juízo Final, atirando-os ao inferno. Depois, foi acolhido pela sociedade "Os Filhos da Alegria", cujos integrantes, "sensatos, espirituosos e cheios de vida", uma vez por semana "comportavam-se como loucos, castigando-se reciprocamente mediante

\footnotetext{
${ }^{60} \mathrm{Idem}$, ibidem, p. 280.

${ }^{61}$ François Rabelais. Gargântua e Pantagruel. Belo Horizonte: Itatiaia, 2003.

${ }^{62} \mathrm{~J}$. W. Goethe, Os anos de aprendizado de Wilhelm Meister, op. cit., p. 265.

${ }^{63} \mathrm{Idem}$, ibidem, p. 266.
}

143 | D O S S I Ê : ROMANCE DE FORMAÇ̃̃O - CAMINHOS E DESCAMINHOS DO HERÓI 
representações alegóricas daquilo que, durante os outros dias, haviam observado de insensato neles próprios e nos outros" ${ }^{64}$. Nessas ocasiões, Serlo podia exercer com liberdade seu talento para a imitação e sua verve mordaz, o que o tornou imprescindível para as atividades da excêntrica sociedade. Em Rabelais, são muitas as cenas de surras, espancamentos e despedaçamentos, assim como são importantes a loucura e personagens loucos. Conforme analisa Bakhtin, ambos elementos exercem papel fundamental no sistema de imagens carnavalizado criado pelo escritor, em que o desmascaramento, o destronamento e a morte do que é velho e ultrapassado pressupõem o surgimento de algo novo.

Serlo segue em busca de aperfeiçoar sua arte "assimilando características de todas as obras e de todos os atores" 65 e aprendendo "aquilo que tão poucos atores parecem ter idéia: economizar seus órgãos e gestos". Obtém sucesso crescente, a despeito do cinismo decorrente da "íntima frialdade de sua índole"66. A dedicação e o empenho para receber o aplauso incondicional do público acabaram por transformá-lo em um consumado ator, capaz de transmitir "verdade, liberdade e espontaneidade" em suas apresentações, ao passo que no contato interpessoal mostrava-se "artificial e dissimulado"67. Diferentemente de Wilhelm, que encarava com extrema seriedade o trabalho teatral, buscando "fixar regras explícitas, definir o justo, belo e bom e o merecedor de aplauso", Serlo agia com certa displicência, porém "sabia, por meio de uma história ou de uma facécia, apresentar a explicação mais completa e satisfatória, instruindo ao mesmo tempo em que distraía seus ouvintes" 68

Desse modo, Goethe pontua o seu paradigmático romance de formação com episódios que problematizam a questão e a relativizam, abrindo o leque de possibilidades interpretativas. "Tudo que nos acontece deixa-nos rastros, tudo contribui, ainda que de maneira imperceptível, para nossa formação"69, diz o preceptor de Wilhelm, afirmação que corrobora o aspecto dialógico da aprendizagem. Também Riobaldo estabelece um intenso diálogo consigo mesmo, com a sua história, com o seu tempo, com o seu lugar e com a humanidade e as ideias com as quais conviveu, percorrendo uma trajetória de desenvolvimento que, ao contrário de visar um fim, estende-se e se aprofunda. "Vivendo, se aprende; mas o que se aprende, mais, é só a fazer outras maiores perguntas" 70 .

\footnotetext{
${ }^{64}$ Idem, ibidem, p. 266.

${ }^{65} \mathrm{Idem}$, ibidem, p. 267.

${ }^{66} \mathrm{Idem}$, ibidem, p. 268.

${ }^{67} \mathrm{Idem}$, ibidem, p. 269.

${ }^{68} \mathrm{Idem}$, ibidem, p. 269.

${ }^{69} \mathrm{Idem}$, ibidem, p. 406.

${ }^{70}$ J. G. Rosa, Grande sertão: veredas, op. cit., p. 312.
}

144 I D O S S I Ê : ROMANCE DE FORMAÇ̃̃O - CAMINHOS E DESCAMINHOS DO HERÓI 
Chamado por Günter Lorenz de "Wilhelm Meister do sertão" 71, o próprio Guimarães Rosa enumera as etapas de sua formação: "Como médico conheci o valor místico do sofrimento; como rebelde, o valor da consciência; como soldado, o valor da proximidade da morte..." E acrescenta a diplomacia, o trato com cavalos, vacas, religiões e idiomas como os elementos que configuram seu mundo interior. ${ }^{72}$ Para o autor, Grande sertão: veredas significou "o término de um desenvolvimento e, ao mesmo tempo, algo que um dia, espero, levar-me-á à meta final"73 Entretanto, haverá final para o autor e para os leitores de uma narrativa que se encerra com o símbolo do infinito? Que com sua prosa poética abre caminhos para que cada um possa encontrar o "homem humano" em seu caminho de aprendizado? Assim, consideramos Grande sertão: veredas um romance de formação e de transformação ao propor uma travessia que não tem ponto de partida nem de chegada, pois é uma fonte contínua e inesgotável de autodescoberta e autorreflexão.

Maria Cecilia Marks é doutora em Letras (Teoria Literária e Literatura Comparada) pela Universidade de São Paulo. Possui mestrado em Letras (Teoria Literária e Literatura Comparada) pela Universidade de São Paulo (2012) e graduação em Comunicação Social pela Faculdade Cásper Líbero, com habilitação em Jornalismo (1999). Tem experiência na área de Comunicação, com ênfase em Jornalismo Especializado, tendo atuado como repórter, redatora e editora em diversas publicações e na concepção e desenvolvimento de projetos editoriais. Já colaborou em revistas da grande imprensa e em publicações segmentadas, além de trabalhar com preparação de originais, redação, revisão e edição de livros. Contato ceciliamarks@uol.com.br.

${ }^{71}$ Günter Lorenz. "Diálogo com Guimarães Rosa". In: João Guimarães Rosa. Ficção completa. Volume I. Rio de Janeiro: Nova Aguilar, 1995, p. 35.

${ }^{72}$ Idem, ibidem, p. 31-32.

${ }^{73}$ Idem, ibidem, p. 58. 